\title{
JUXTAPOSITION OF THE ATRIAL APPENDAGES : TWO CASES OF AN UNUSUAL CONGENITAL CARDIAC DEFORMITY
}

\author{
BY \\ ALLAN ST. J. DIXON \\ From the Clinical Research Unit, Guy's Hospital and the Srecial Unit for Juvenile Rheumatism, Canadian Red Cross \\ Memorial Hospital, Taplow, Bucks \\ Received September 21, 1953
}

The two hearts here reported showed opposite manifestations of disordered bending of the primitive cardiac tube at an early stage of ontogeny. In both, the atrial appendages lay side by side instead of encircling the roots of the great vessels. In the first the two appendages lay to the right of both great vessels, a condition that does not appear to have been described. In the other both appendages lay to the left of both great vessels, a condition that has been reported eleven times, and with the present case forms a group with several other pathological features in common, including a decrease in the volume of the pulmonary circulation. Further similar cases are likely to be met as a result of the present interest in cardiac surgery, and among them may be some that can be helped by systemic-pulmonary shunt operations.

\section{CASE with both Atrial Appendages on the Right}

Case 1. A female child, aged three weeks, who had been deeply cyanosed and very ill since birth, died in the maternity hospital where she was born. No investigations were carried out before death. Routine autopsy (Canadian Red Cross Memorial Hospital. P.M. 46/49) was carried out by Dr. Francis Scott, to whom I am indebted for the specimen of the heart. As well as the cardiac condition, there was an abnormality of rotation of the gut, in which the coils of small intestine and their mesentery took origin from the posterior abdominal wall above the origin of the mesocolon. Death was due to congestive cardiac failure and to atelectasis of the lungs.

\section{ANATOMical Description}

Cardiac hypertrophy; primitive arrangement of chambers of heart whereby both atrial appendages lie side by side to the right of both great vessels; common pulmonary vein; right-sided vena cava emptying into left atrium; atrial septal defects; tricuspid hypoplasia; hypoplastic right ventricle; partial transposition of the great vessels; congenital coarctation of the arch of the aorta; patent ductus arteriosus.

The heart and the roots of the great vessels were removed from the body and preserved in formol saline for further study. The heart had been opened at autopsy by three incisions, one through each great vessel and the adjoining ventricle and one into the left atrium. For descriptive purposes the heart is deemed to be held in the standard anatomical position so that ventral is equivalent to anterior, dorsal to posterior, cephalic to superior, and caudal to inferior. All measurements are of the fixed specimen.

The transverse diameter of the anterior aspect of the heart is $65 \mathrm{~mm}$. (see Fig. 1 and 2). The large left ventricle occupies all of the anterior aspect of the heart except at its upper right border where it is overlapped by the atrial appendages. The base of the heart is formed (from right to left) of a small portion of the right atrium $(5 \mathrm{~mm}$.) continuous with the origin of the superior vena cava. Next, a space of $5 \mathrm{~mm}$. in diameter represents. part of the left atrium where it receives the left atrial appendage. This space is bounded on its left by the ascending aorta, and to the left of the latter is the pulmonary trunk. The posterior aspect of 


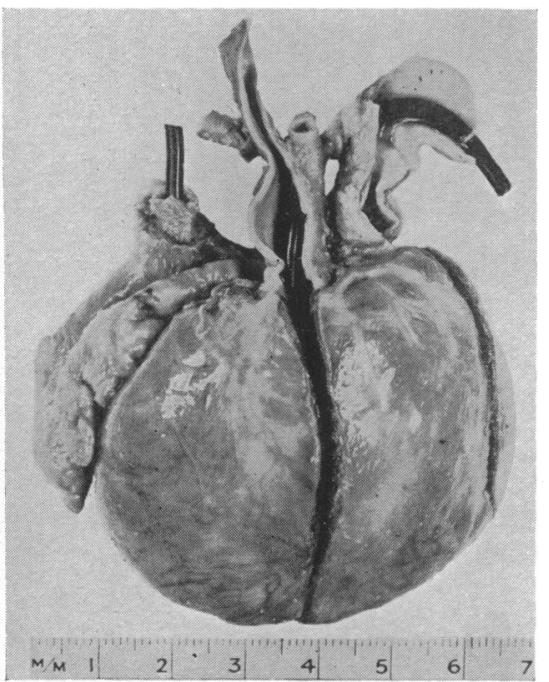

Fig. 1.-Photograph of anterior aspect of specimen. Case 1.

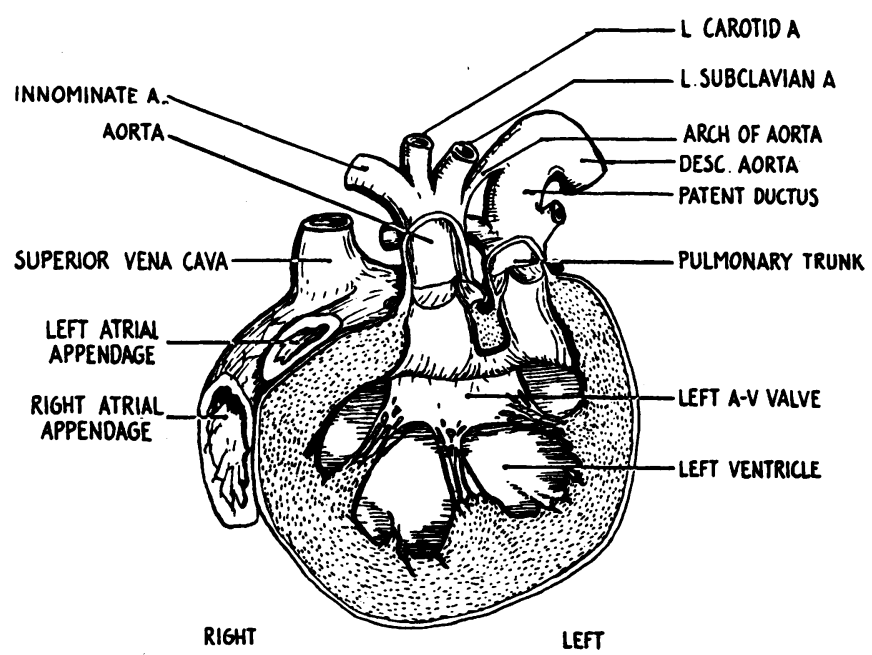

FIG. 2.-Anterior coronal section, through the great vessels and left ventricle, viewed from in front. Case 1. the heart is made up of the left ventricle to the left with the atrium and right ventricle on the right. Fig. 3 is a diagram of the superior aspect of the heart and of the great vessels at their entry or origin. Illustrations of this specimen (Fig. 2, 4, and 5) are drawings of supposed sections of the heart in planes at right angles to the plane of the paper in this figure, and are indicated here by straight lines with arrows to show the direction of view.

The right atrium (Fig. 4) is small, and measures $25 \mathrm{~mm}$. high by $10 \mathrm{~mm}$. wide at its widest point. Above, the anterior wall of the right atrium is continuous with the anterior wall of the left atrium through a small septal defect. The postero-lateral wall of the right atrium is a curved surface perforated in its middle third by the mouth of the right atrial appendage; inferiorly it terminates at the right A-V orifice. The atrial septum is thin and delicate and crescent shaped. Its anterior edge joins the anterior wall of the right atrium throughout its length, except superiorly, where a sickle-shaped free margin encloses a defect (Fig. 5). A probe passed through this into the left atrium lies near the mouth of the superior vena cava. Inferiorly, the septum is curved to the left so as to lie in a transverse plane. Here it is in superior relationship to the tricuspid orifice, and shows a second and smaller defect (Fig. 5). The atrial septum ends in a fibrous bar of tissue which completes the left part of the tricuspid valve ring by bridging across the gap between the posterior wall of the right ventricle and the ventricular septum.

No great veins open into the right atrium. The right atrial appendage measures $10 \times 35 \mathrm{~mm}$., and is closely applied to the back of the left appendage. Both appendages lie in a broad and shallow groove in the ventricular muscle. The right A-V orifice (Fig. 4) measures $25 \mathrm{~mm}$. in circumference and lies at the lower end of the right atrial cavity. It is guarded by three valve leaflets placed anteriorly, left and right. These leaflets are of equal size, fused with each other at their adjoining edges, measure about $8 \times 4 \mathrm{~mm}$., and are irregularly thickened.

The left atrium (Fig. 5) is larger than the right and measures $4 \times 4 \mathrm{~cm}$. Its anterior wall is pierced obliquely by the orifice of the left atrial appendage, and superiorly and to the right it is continuous with the superior vena cava. However, beneath the opening of the latter is a membraneous horizontal shelf measuring $8 \times 8 \mathrm{~mm}$., which springs from the anterior wall of the left atrium and lies with its free edge posteriorly. Blood flowing from the superior vena cava would be directed by this shelf in a backwards direction. It 


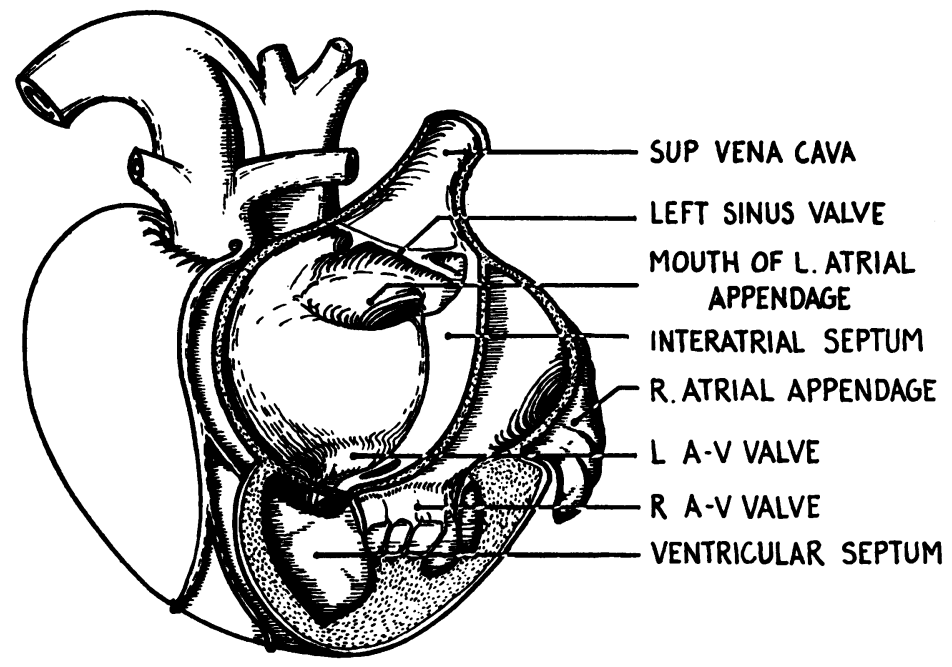

Fig. 4.-Posterior coronal section, viewed from behind, through right and left atria and the rignt ventricle. Case 1.

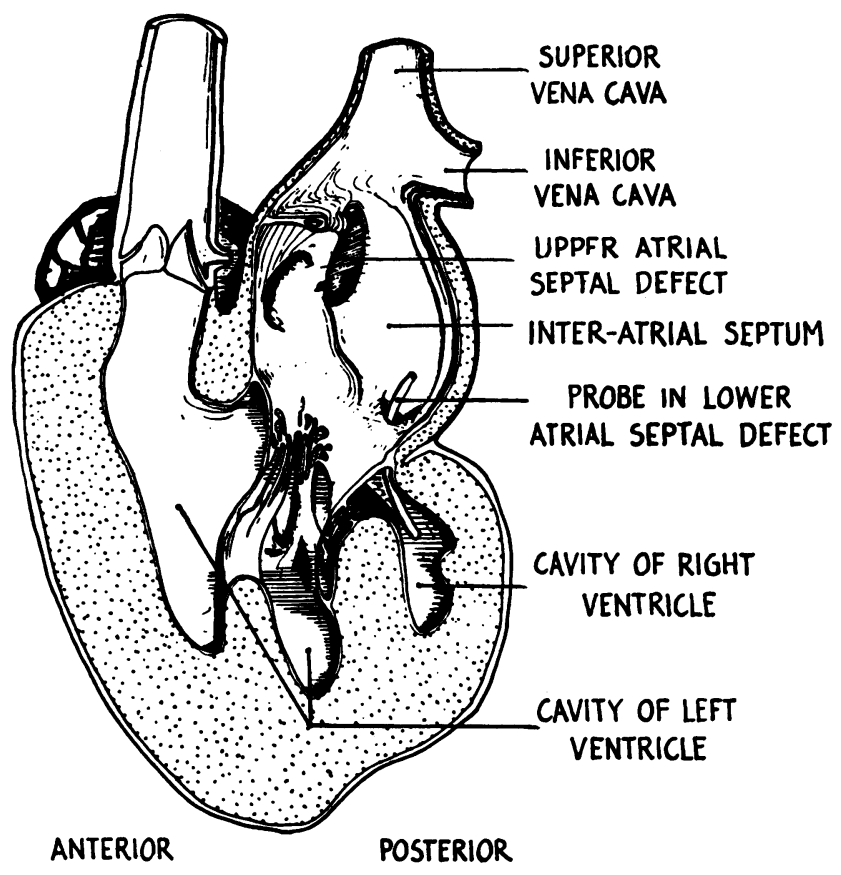

Fig. 5.-Sagittal section, viewed from the left, through left atrium, left ventricle, and aorta. Case 1.

appears that there is a failure of final incorporation of the sinus venosus into the right atrium, and that the horizontal shelf described is the left sinus valve, while where the superior vena cava enters is likely to be what should have become the coronary sinus. The inferior vena cava enters the posterior wall of the left atrium above the level of the left sinus valve. A curious feature of the structure of this left sinus valve is that its free edge divides towards the right to enclose a funnel-shaped space which is prolonged to the left as a tube. A probe passed along this tube lies within the free edge of the shelf and passes out again into the 
cavity of the left atrium by a small ostium. Below the shelf which separates off a sinus venosus is the smaller defect in the atrial septum. The posterior wall of the left atrium shows the opening of the common pulmonary vein, inferiorly and to the left. Superiorly and to the right it receives the inferior vena cava.

The common pulmonary vein is formed $5 \mathrm{~mm}$. from the left atrium by the union of left and right pulmonary veins. The base of the left atrium is almost entirely occupied by the left $A-V$ orifice, but posteriorly the atrial septum (whose lower end bends horizontally and to the left) separates the cavity of the left atrium (above) from the cavity of the right atrium (below) just above the right A-V valve. The left A-V (mitral) orifice measures $65 \mathrm{~mm}$. in circumference, and is guarded by anterior and posterior leaflets. The anterior leaflet is thin and translucent and measures $35 \times 10 \mathrm{~mm}$. The posterior leaflet is slightly less translucent; it measures $30 \times 8 \mathrm{~mm}$. and hangs like a curtain in front of the ventricular septal defect (Fig. 5).

The right ventricle (Fig. 4) is a vestigial chamber occupying the right posterior part of the heart. Its cavity is widest at the right A-V orifice, where it is $20 \mathrm{~mm}$. in diameter; it then passes inferiorly and to the left for $25 \mathrm{~mm}$. to taper to a point. Its anterior wall is formed by the muscular ventricular septum lying approximately in the coronal plane (see Fig. 5), which is perforated superiorly and to the left by a circular defect measuring $5 \mathrm{~mm}$. in diameter-the sole outlet for blood from the right ventricle. The muscle lining the right ventricle is finely trabeculated and the cavity of this chamber (in the fixed specimen) is almost entirely occupied by the single papillary muscle and by the leaflets of the tricuspid valve.

The cavity of the left ventricle (Fig. 2 and 5), is large, measuring $45 \mathrm{~mm}$. across by $30 \mathrm{~mm}$. from base to apex. Its walls are $10 \mathrm{~mm}$. thick and are coarsely trabeculated. The origins of the two great vessels lie side by side anteriorly and superiorly, the aorta to the right, the pulmonary trunk to the left, separated from each other by a thick ridge of muscle in a sagital plane; both are separated from the mitral orifice by another thick ridge of muscle lying in a coronal plane. Together these two muscular ridges form a $T$, the bar of which separates an outflow tract of the ventricle from the small inflow tract, and the upright part of the $\mathrm{T}$ subdivides the outflow tract into aortic and pulmonary components. The muscle wall of this outflow tract is smooth and not trabeculated. It is continuous above with the lining of the two great vessels.

The aortic valve measures $4 \mathrm{~mm}$. in diameter. It has three cusps placed in the left anterior, left posterior, and right lateral positions. The two coronary arteries spring from the sinuses of the left anterior and left posterior cusps. The valve lies on a level with the junction of aorta and cardiac muscle. The aorta itself passes upwards and at a distance of $15 \mathrm{~mm}$. from the valve (and from its origin) gives off right innominate, left carotid, and left subclavian arteries. The arch of the aorta shows a congenital coarctation (Type 1 of Evans, 1933) patent to a fine probe; it joins a descending aorta of normal size.

The pulmonary valve is larger than the aortic and is $5 \mathrm{~mm}$. in diameter. It has three cusps set anteriorly, left posteriorly, and right posteriorly. The pulmonary trunk leaves the muscular substance of the heart to the left of and slightly behind the aorta. It splits almost immediately to give off right and left pulmonary arteries, but its lumen is carried on upwards with out loss of width, by a large patent ductus arteriosus, the walls of which are twice as thick as those of the aorta and pulmonary trunk; it is subsequently continuous with the descending (left-sided) aorta.

The anterior coronary artery (Fig. 6) has three main branches which are distributed to the anterior surface of the left ventricle. The posterior coronary artery passes backwards splitting into three main branches distributed to the posterior wall of the ventricle. One of these descending branches lies in relationship with the interventricular septum. The coronary sinus measures $3 \mathrm{~mm}$. in diameter at its mouth. It ascends in the shallow inter-ventricular groove in the right wall of the ventricle, then empties into the left atrium between the origins of the two atrial appendages.

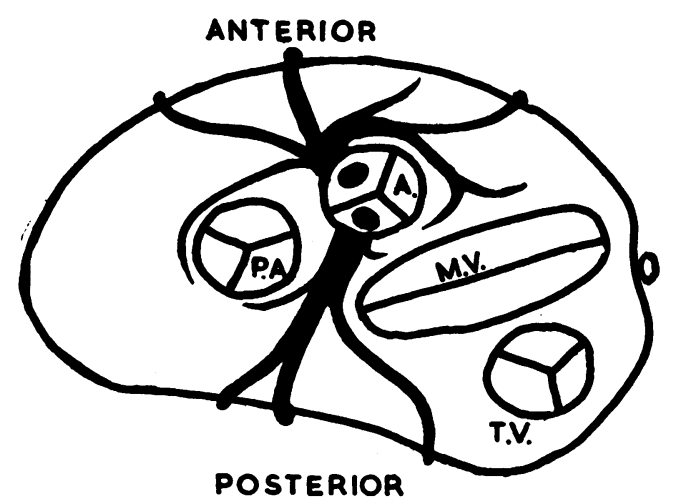

FIG. 6.-Diagram of the course of the coronary vessels projected onto the plane of the coronary sulcus. Case 1.

\section{Case with both Atrial Appendages on the Left}

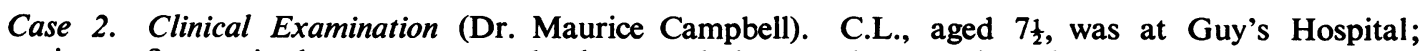
cyanosis was first noticed at one year, and subsequently increased. Exercise tolerance was very limited.

On examination she was undersized and intensely cyanotic with extreme clubbing of fingers and toes. 
Her pulse rate was 108 , regular, and her blood pressure $105 / 60 \mathrm{~mm}$. $\mathrm{Hg}$. The heart was enlarged, with the apex beat outside the midclavicular line. There was a systolic thrill and a short harsh systolic murmur in the second left interspace and triple rhythm just inside the apex, with the third sound early in diastole. The liver edge was felt $2 \mathrm{~cm}$. below the costal margin, and the spleen was just palpable. The blood showed polycythæmia (hæmoglobin $150 \%$ ) and a low colour index $(0 \cdot 75)$.

An electrocardiogram showed marked left axis deviation with tall $P$ waves in leads I and II.

A tracing of the cardiac outline is shown in Fig. 7. The cardiothoracic ratio was $10.5 \mathrm{~cm} . / 20.5 \mathrm{~cm}$. The right cardiophrenic angle was increased in size and depth owing to absence or displacement of the right ventricular shadow. On fluoroscopy (Dr. Maurice Campbell) the left ventricle was enlarged and the aorta, which was left sided, appeared to arise far over to the right. Increased vascular shadows in the lung fields were diffuse and more like a collateral than the pulmonary circulation.

On cardiac catheterization (Dr. G. Zak and Dr. H. E. Holling) the catheter was passed into the right atrium; the right ventricle was not entered, but the catheter passed through an atrial septal defect into the left side of the heart and thence into a chamber which was under high pressure $(160 / 20)$ and was presumed to be the left ventricle, although no outlet from it was found. A blood specimen withdrawn from this chamber showed less cyanosis than that found

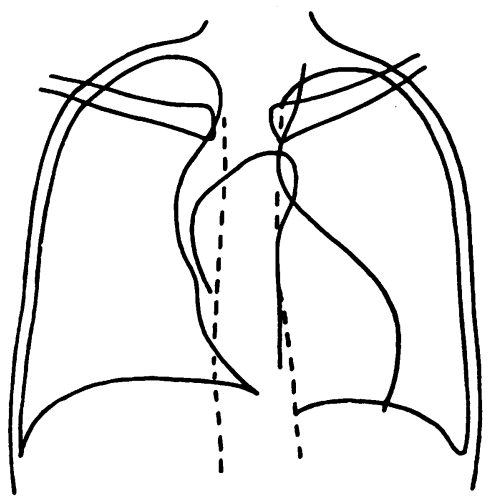

FIG. 7.-Tracing of cardiac silhouette. Case 2. in the right atrium; blood gas analyses proved technically unsatisfactory.

Dr. T. H. Hills' report on the angiocardiogram was as follows. The right ventricle and aorta are filled at two seconds, but little dye appears in the pulmonary vessels until three seconds, and the filling is never good. There is a large right-to-left shunt. The heart is opaque to its left border at four seconds which may be due to dye shunting from right to left atrium in addition to shunt into the dextraposed aorta (Fig. 8).

In retrospect the position of the atrial appendages in relationship to the aorta can be made out in the two-second picture, when dextraposed aorta, right ventricle, and both atria are filled, while the left ventricle presents as a filling defect into which obtrudes the shadow of the left atrial appendage.

Course. Surgical anastamosis of the pulmonary and systemic circulations was not attempted and increasingly severe attacks of cyanosis and loss of consciousness led to her death within a few months.
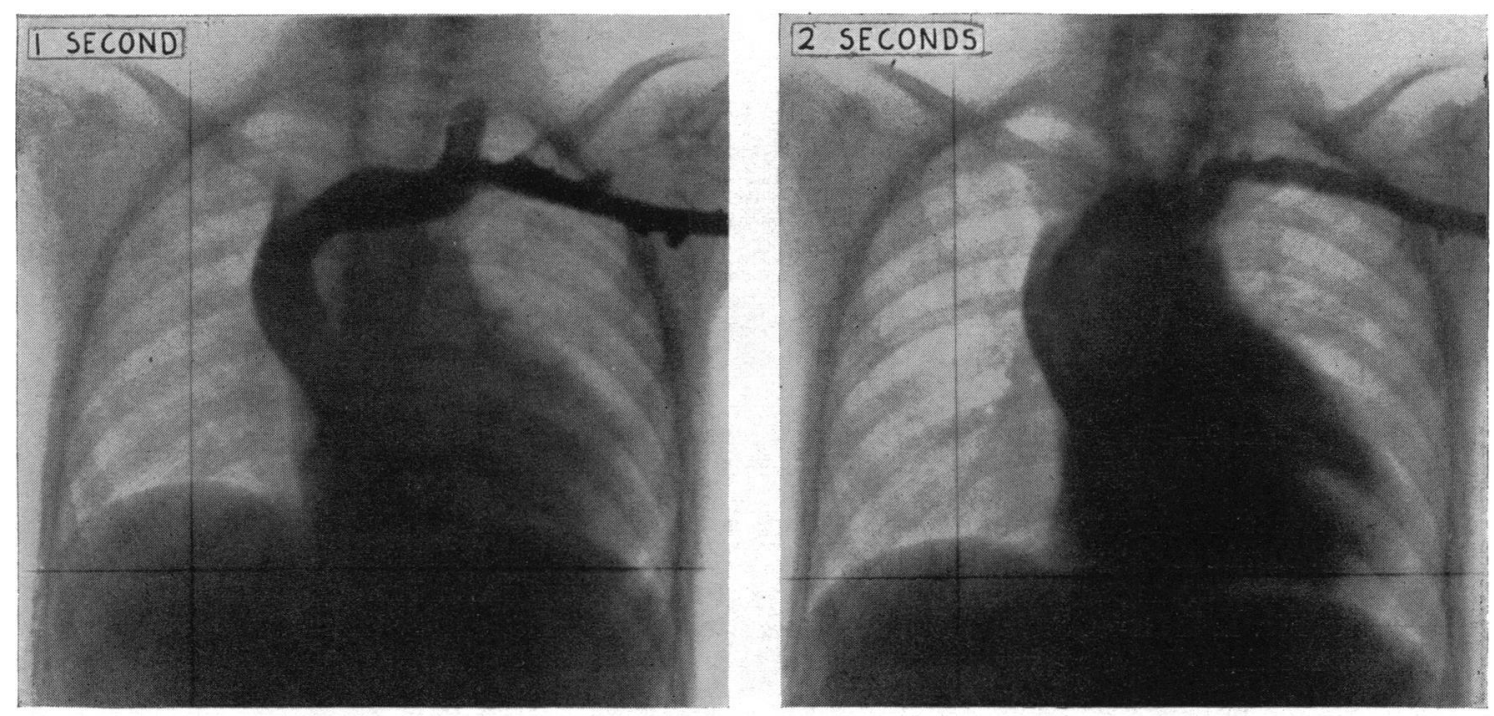

FIG. 8.-Reproduction of angiocardiograms at 1 and 2 seconds after injection of the diodone. Case 2. 


\section{ANATOMICAL DESCRIPTION}

Cardiac hypertrophy; primitive arrangement of chambers whereby both atrial appendages lie to the left of both great vessels; atrial septal defect; common pulmonary vein; left ventricular preponderance; accessory septa in the right ventricle; partial transposition of the great vessels; subvalvular stenosis of the pulmonary trunk.

The collateral circulation to the lungs was injected with carmine gelatine soon after death, and the thoracic viscera were removed entire. Apart from severe venous congestion throughout the body, and clubbing of the fingers and toes, no abnormalities were found other than in the heart. The description that follows is of the fixed, injected specimen, held in the standard anatomical position as in Case 1.

The transverse diameter of the heart (Fig. 9) is $9 \mathrm{~cm}$. The very large aorta, arching upwards, backwards, and to the left over the hilum of the left lung, begins at the extreme right upper part of the heart, so that the aorta and right border of the heart form one continuous curve. An undersized pulmonary trunk emerges from the heart behind the aorta, and passes upwards and to the left. To the left of both vessels are the two atrial appendages, which lie side by side along the base of the heart and overhang the ventricles. The right appendage extends for $50 \mathrm{~mm}$. along the base and the left appendage, which is much narrower, for $15 \mathrm{~mm}$. The left border of the heart is made up of ventricular muscle. Thus the base of the heart is made up of aorta, with the pulmonary trunk behind it, the right atrium, and the left atrium, in that order from right to left.

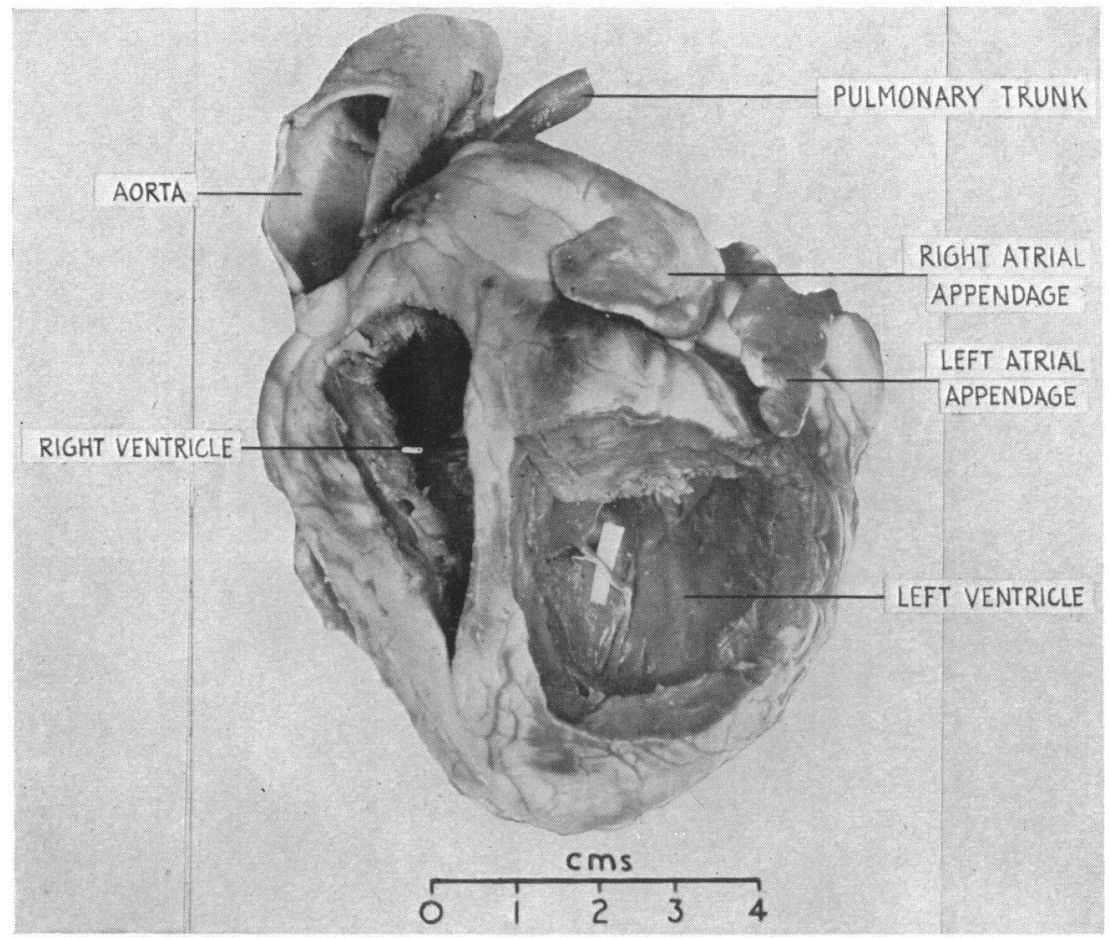

FIG. 9.-Photograph of anterior aspect of specimen. Windows have been cut in the anterior walls of ventricles. Case 2.

Fig. 10 represents the superior aspect of the heart and the great vessels at their origin or entry. As with Case 1, Fig. 3, all subsequent drawings except Fig. 12 are of supposed sections through the heart at right angles to the plane of the paper in this diagram; they are indicated by lines and arrows to show the direction of view: for Fig. 12 the heart has been opened by a left-sided incision to display the septa.

The right atrium (Fig. 13) is large, measuring $50 \mathrm{~mm}$. antero-posteriorly, $75 \mathrm{~mm}$. laterally (including the appendage) and $50 \mathrm{~mm}$. in height. It receives the venæ cavæ and coronary sinus in the normal manner. The atrial septum is represented by a thin rim of tissue, lying in the coronal plane, which encloses a wide atrial septal defect measuring $15 \times 23 \mathrm{~mm}$. The right A-V orifice is behind and slightly to the left of the 
origins of the great vessels. It measures $50 \mathrm{~mm}$. in circumference and bears three cusps, posterior, medial, and anterior. The medial cusp shows two small warty vegetations, measuring $3 \times 3 \mathrm{~mm}$. on its atrial side. The anterior wall of the right atrium is indented by the origins of the great vessels.

The left atrium (Fig. 11 and 12) is smaller. It receives the common pulmonary vein which is formed $10 \mathrm{~mm}$. from the atrium by the union of left and right pulmonary veins, themselves formed by the union of upper and lower tributaries on each side. The left A-V opening is $70 \mathrm{~mm}$. in circumference and bears two normal cusps, posterolateral and antero-medial.

The ventricle (Fig. 11) is unequally divided into small right and large left portions by an incomplete but thick septum, which meets the lower part of the ventricular cavity $20 \mathrm{~mm}$. from the apex. The septum is composed of a thick solid bar of muscle superiorly, and of a spongy trabecular formation recalling the embryonic

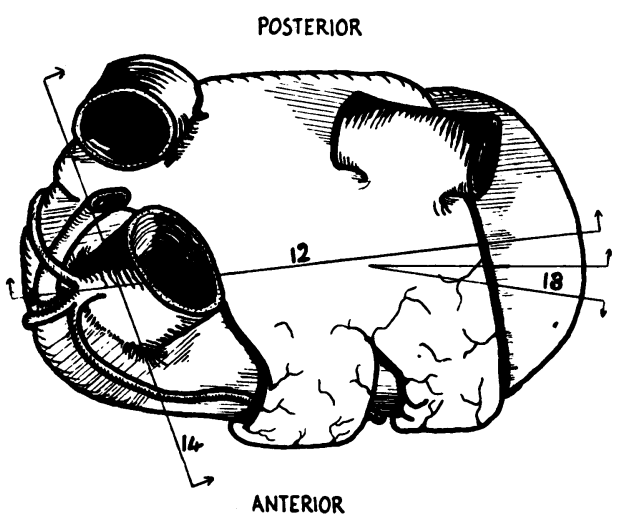

FIG. 10.-Superior aspect of the heart and the great vessels at their entry or origin. Straight lines indicate the planes of figures but $12=$ Fig. $11,13=$ Fig. 12, and $14=$ Fig. 13 ; arrows the direction of view. Case 2.

state of the heart muscle inferiorly. Viewed from the left side, it extends upwards for a distance of $30 \mathrm{~mm}$., leaving a ventricular septal defect $15 \mathrm{~mm}$. in diameter (Fig. 12) posteriorly and superiorly between the A-V valves. In addition to this main defect, there is, when the septum is looked at from the left, a

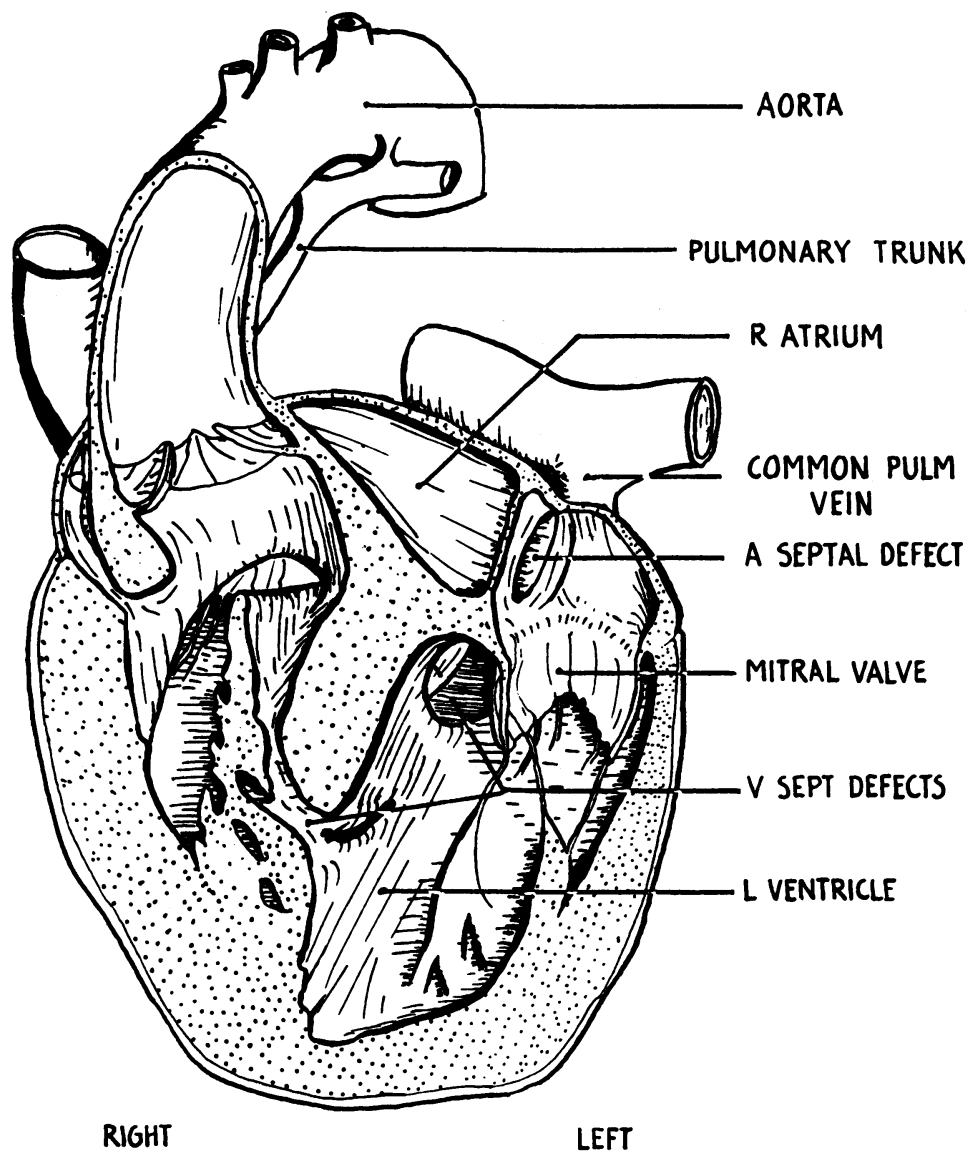

Fig. 11.-Anterior coronal section through both atria and both ventricles, viewed from in front. Case 2. 


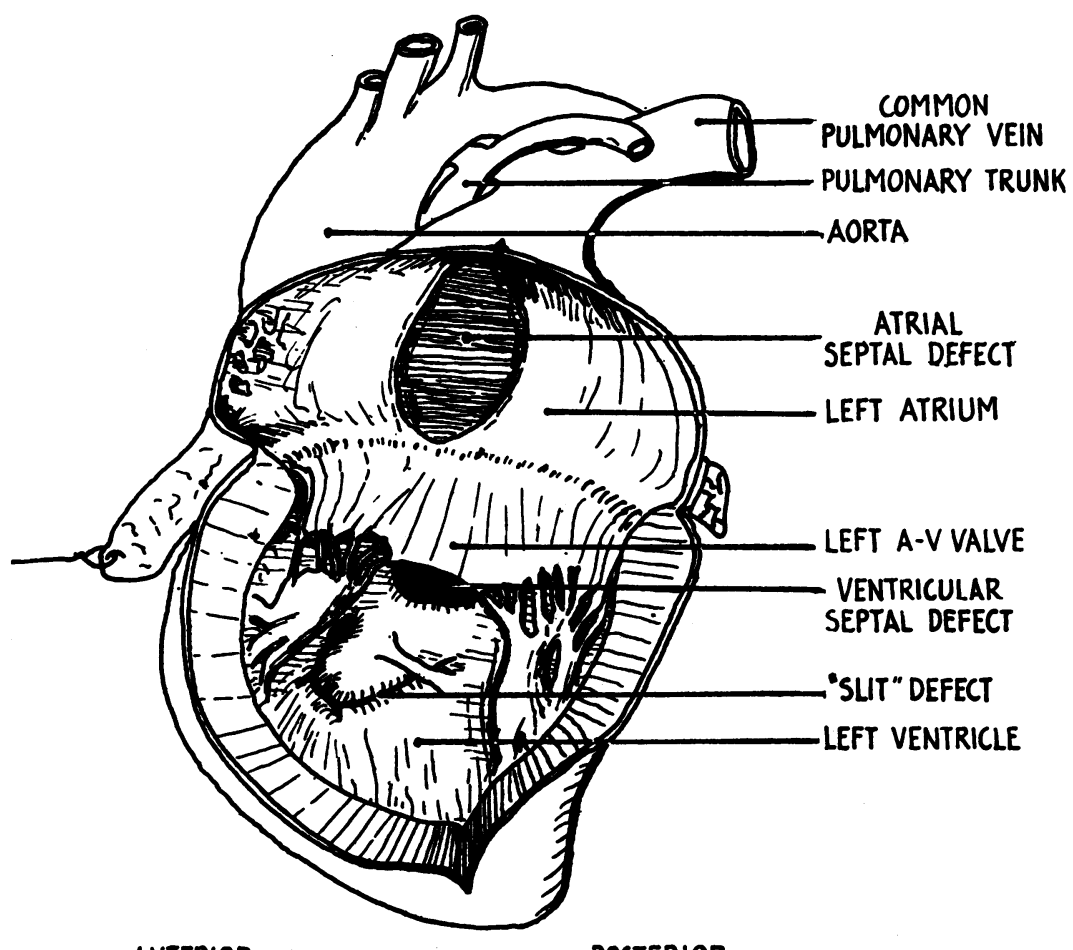

ANTERIOR

POSTERIOR

FiG. 12.-The heart split open down its left border, to show the left aspect of the atrial septum, the atrial septal defect, the mitral valve, the main ventricular septal defect partly covered by the mitral valve, and below it the slit-like ventricular septal defect crossed by a trabeculum. Case 2.

long slit-like defect the upper end of which is widened so that a narrow channel passes upwards, backwards, and to the right to end in the anterior part of the right ventricle. The rest of the slit-defect shows muscular walls so closely applied to each other that there is only a potential channel. The cavity of the left ventricle (Fig. 11 and 12) is large and somewhat pear-shaped, measuring $60 \mathrm{~mm}$. vertically and between 20 and $30 \mathrm{~mm}$. transversely. The walls show the fine trabeculation normally characteristic of the right ventricle. No great vessels issue from this cavity.

The right ventricle (Fig. 11 and 13) is small, measuring $25 \times 25 \mathrm{~mm}$. in width and from front to back. It occupies the upper and right part of the heart. The walls are $6 \mathrm{~mm}$. thick at the apex, and $10 \mathrm{~mm}$. at the medial wall. The right ventricular face of the ventricular septum (Fig. 13) is smaller than the left, and measures $20 \mathrm{~mm}$. in height, and shows the main defect posteriorly. In the extreme upper part of the right ventricular cavity, below the mouth of the aorta, the septum is smooth-walled, only $4 \mathrm{~mm}$. thick, and separates right ventricle from right atrium and the beginning of the right atrial appendage. Below this, the walls show the coarse trabeculae normally characteristic of the left ventricle.

Both great vessels (Fig. 11) arise from the anterior superior part of the right ventricle. Between the tricuspid valve behind and the origins of the great vessels in front, a thick smooth band of muscular tissue arches over the roof of the right ventricular cavity from its right wall near the floor to join the septum in front of the main defect. This clearly divides the inflow part of the right ventricle containing the tricuspid valve from an outflow chamber, or aortic ventricle. Its left end straddles, saddle fashion, the posterior end of the free edge of a second muscular shelf which divides the floor of the right ventricle. These two thick muscular shelves lie at an angle of $\mathbf{4 5}$ degrees to each other. The true relationship of the muscular shelf that divides the floor of the right ventricle to the ventricular septum, as seen from the left ventricle, is shown in Fig. 11. There is an overlap between the upper and lower parts of the septum and it is this overlap projecting into the right ventricle which appears as the muscular ridge in the floor of that cavity. 


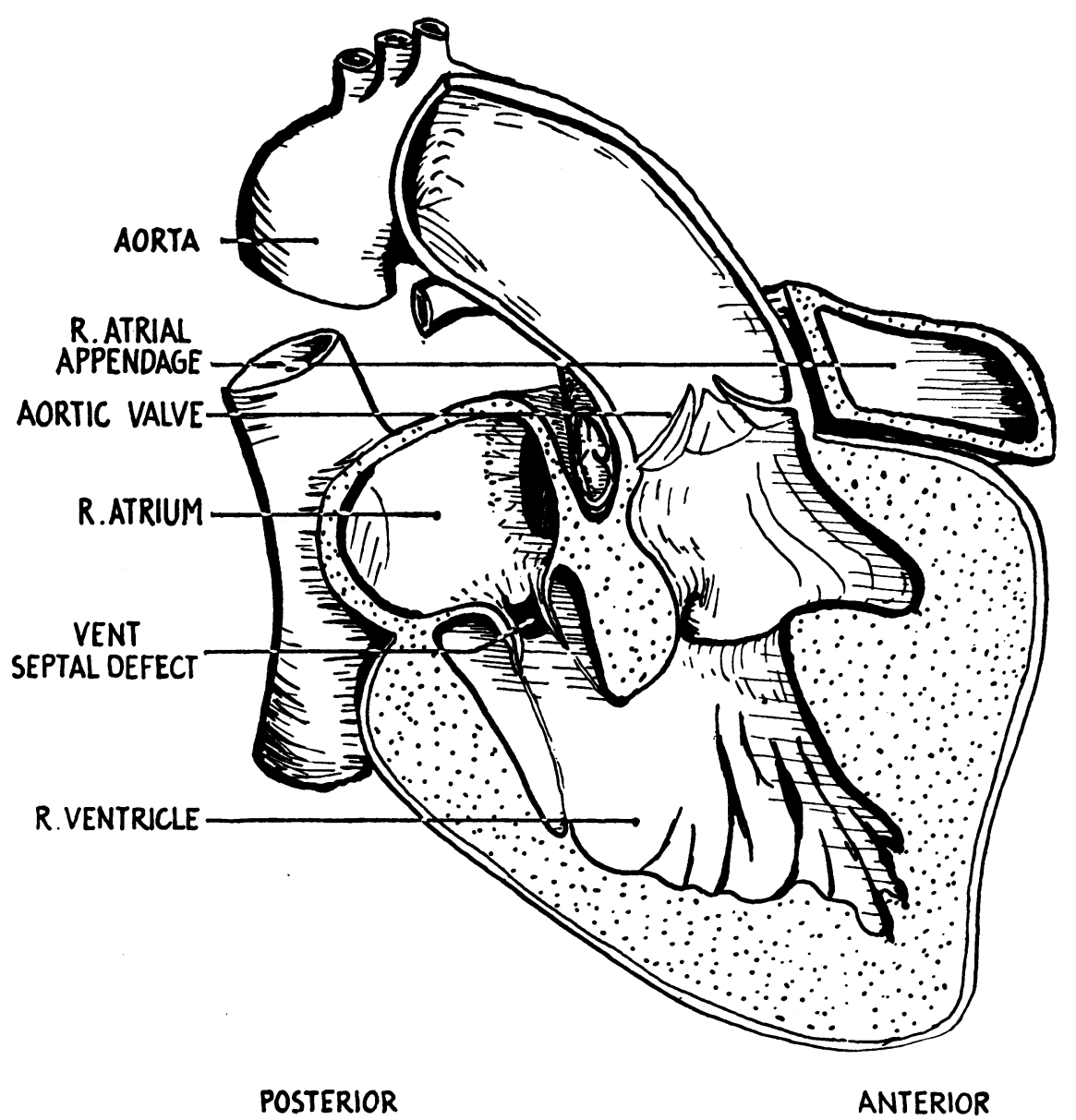

Fig. 13.-Sagittal section through the right atrium and right ventricle viewed from the right. Case 2.

The aorta arises between the undersized pulmonary trunk and the right atrium (Fig. 11) and is directly above the opening of the upper part of the slit-defect, which is now seen to be the most direct (though not the widest) route for blood from the left ventricle to the aorta. Fig. 13 shows the more complicated path taken by the greater part of the left ventricular outflow through the main ventricular septal defect. The aortic valve measures $65 \mathrm{~mm}$. in circumference and bears three normally formed cusps placed in posterior, right anterior, and left anterior positions.

The pulmonary trunk (Fig. 11) measures $20 \mathrm{~mm}$. in circumference at the level of the valve which lies behind the ascending aorta, but only admits a 2-mm. probe where it emerges from the right ventricle. From its point of origin it spirals in an upward, backward, and leftward direction, behind the aorta. It bears a small tricuspid valve whose leaflets have not separated. The left and right pulmonary arteries are normal in position and each is as large as the parent trunk. They are filled with dye by back injection from the bronchial arteries. A closed ligamentum arteriosum joins the left pulmonary artery to the arch of the aorta.

There are two coronary arteries arising from the posterior and left anterior sinuses of Valsalva (Fig. 14). That from the posterior sinus passes forwards to the right of the pulmonary

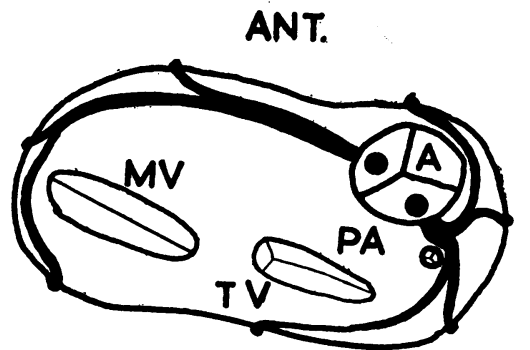

FIG. 14.-Diagram of the coronary arteries projected on to the plane of the coronary sulcus. Case 2. 
trunk. That from the left anterior sinus passes to the left underneath the overhanging atrial appendages. The coronary sinus empties into the posterior aspect of the right atrium after a short course in the posterior coronary sulcus.

\section{Discussion}

The anomaly whereby both atrial appendages lie side by side has received no special name. It seems convenient to call it "juxtaposition of the atrial appendages." Case 1 would then be an example of right juxtaposition and Case 2 of left juxtaposition. Fig. 15 is an extension of a diagram published by Wenner (1909). It shows the stage of ontogeny at which the anomalies described are presumed to have been initiated, that is, at the time of the first folding of the primitive cardiac tube that determines the relative positions of the sinus, atrium, ventricle, and bulbus. The middle series represents a normal folding followed by the development and forward growth of the two

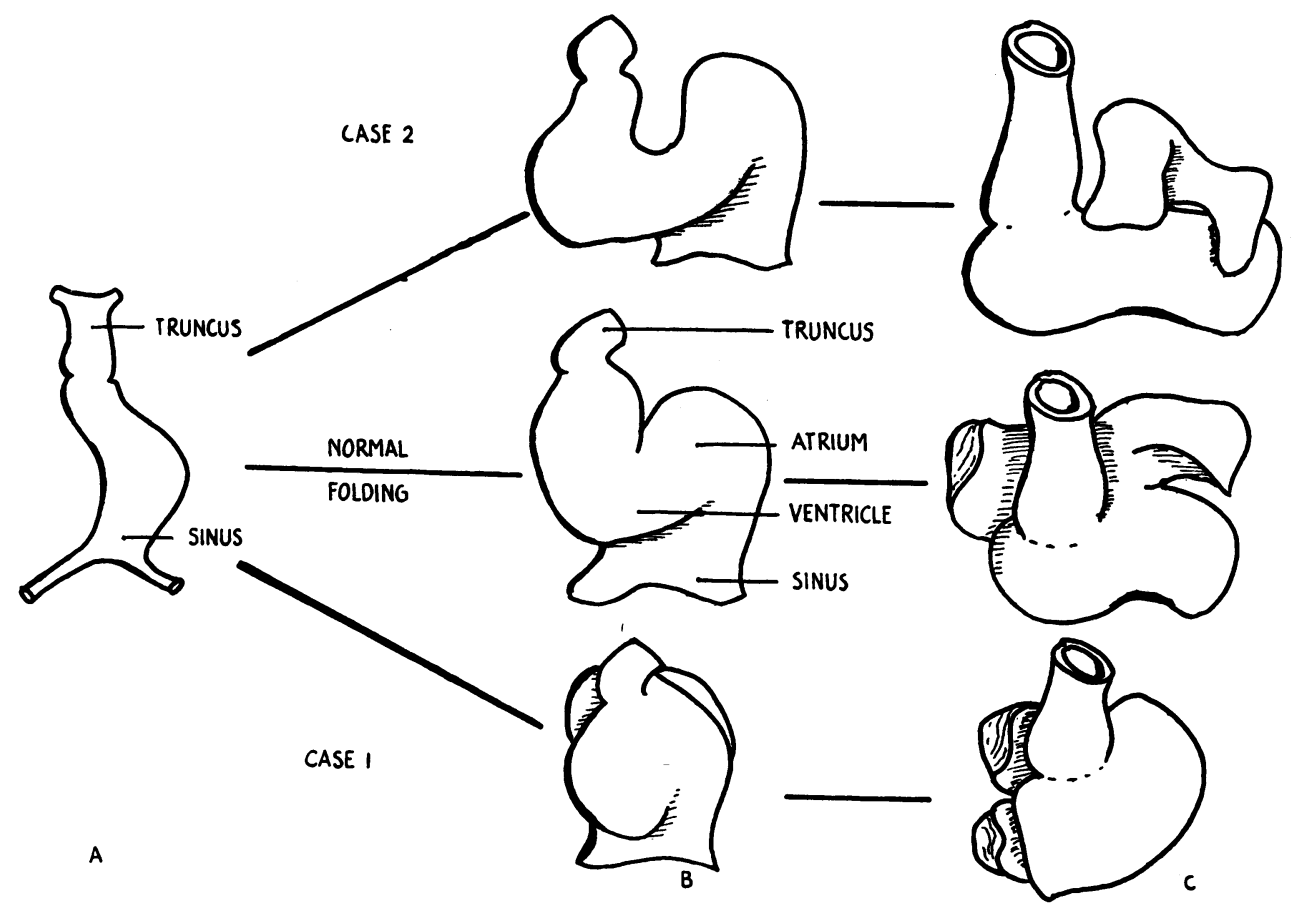

Fig. 15.-Presumptive explanation of anomalies (after Wenner, 1909).

(A) Primitive cardiac tube.

(B) Initial folding determines the relative positions of the cardiac chambers.

(B) The atrial appendages differentiate and grow forwards.

atrial appendages so that they embrace the truncus. The upper series represents a possible explanation of the condition found in Case 2 and the lower series the condition found in Case 1. One cannot say whether disordered bending is in fact the primary fault in the development of these two deformed hearts although this seems a likely explanation. However, once such a disorder has arisen it will clearly have a great influence on the later growth of septa and separation of the heart into right and left channels. In Case 1 (right juxtaposition of the atrial appendages) such septa as have appeared have divided the heart into a very small right atrium and ventricle, receiving no blood and having no special outlet, and a large left atrium and ventricle which, since they receive and discharge the whole blood supply to the heart, function as a bilocular heart. A similar heart does not seem to have been recorded but the most analogous is that reported by Taussig (1947) of a woman who died at the age of twenty-six. The heart showed situs inversus, dextrocardia, and 
cor biloculare, with only rudimentary septa in the atrium and ventricle. The two atrial appendages lay in left juxtaposition, but because of the situs inversus, it is apparent that this case is more nearly the mirror image of Case 1 than similar to Case 2. Neither in Case 1 nor in Taussig's case was there a diminution of blood supply to the lungs, and therefore no possibility that an anastomotic operation of the Blalock type would be of help.

Several other cases of the left-sided variety of juxtaposition of the atrial appendages (as in Case 2) have been previously reported; with Case 2 they form a group of eleven that share certain other features, including a hypoplastic or atretic pulmonary trunk. In some of these (including Case 2), it would have been technically possible to do an anastomotic operation. The reported cases are therefore briefly summarized.

Birmingham (1893) described a heart that showed a remarkable similarity to Case 2. In it, too, the undersized pulmonary trunk, patent only to a fine probe, arose to the right of the aorta. Both vessels sprung from the right ventricle in front of a thick muscular ridge which separated them from the tricuspid orifice. The only differences appear to have been that in Birmingham's case the aortic arch was right-sided, that there was a persistent left superior vena cava (while the pulmonary veins were normal), that the right ventricle was large and tapered, making the apex of the heart lie on the right, and that the ventricular septal defect appears also to have been slightly more anteriorly placed in that it opened directly under the origin of the aorta from the right ventricle.

Wenner (1909) briefly described a case associated with a single ventricle and transposition of the A-V valves.

Dunner (1914) described a case where the true ventricular septum was vestigial, but a false septum present in the right half of the ventricle cut off a " third "ventricle which gave rise to the pulmonary trunk.

Huebschmann (1921) described a case associated with tricuspid atresia. The normal site for the ventricular septum was occupied by a muscular ridge. In addition another septum, complete except for a fine perforation superiorly, cut off a tiny " third ventricle" which gave rise to an undersized but normally placed pulmonary trunk.

Kettler's (1933) case was similarly associated with tricuspid atresia. The ventricular septum was present though defective, but in addition the right ventricle was subdivided by a false septum with a defect inferiorly, cutting off a separate cavity which gave rise to the pulmonary trunk.

Bredt (1936) described two cases. In the first an undersized pulmonary trunk arose to the left of the aorta in front of a false septum arching across the roof of the right ventricle, which cut off the inflow part of the right ventricle containing the tricuspid valve from the outflow part giving rise to the aorta and pulmonary trunk: a muscular ridge subdivided the floor of the right ventricle. Bredt's second case is pictured but not described other than by saying that it was identical with his first case.

Harris and Farber (1939) described a case similar to Bredt's in the position of the pulmonary trunk, but otherwise resembling our Case 2. Again, one of the most marked features was a septum which arched over the roof of the right ventricle and subdivided that cavity into inflow and outflow parts. They also describe a case somewhat similar to that of Dunner, where the false septum dividing the right ventricle was the only one present, the normal septum being represented by a muscular ridge only.

Rogers et al. (1950) reported a case associated with tricuspid atresia. At the age of twelve an anastomotic operation to improve the pulmonary circulation was attempted but the patient died soon after thoracotomy. The ventricle was divided into large left and small right portions by prominent muscular ridges in the roof and floor of that cavity. The pulmonary trunk showed subvalvular stenosis, and took origin to the left of the large aorta.

Excluding Taussig's case, the following defects are constant for the group with left juxtaposition of the atrial appendages. These are: atrial septal defect or defects (ranging from a narrow channel to an absent septum); a marked degree of ventricular septal defect (since the ventricular defect was the only outlet from the left ventricle proper); some degree of stenosis of the pulmonary trunk 
(except in Dunner's case); and partial transposition * of the great vessels. This statement must be qualified by saying that in four cases the right ventricle was subdivided by a false septum, so that the aorta and pulmonary trunk arose from different divisions of the right ventricle.

The presence of accessory septa in the right ventricle is interesting. These are of two types, namely those springing from the floor of the right ventricle so as to divide it in a roughly sagittal plane ( 4 cases) and those springing from the roof of the right ventricle so as to divide it into anterior (outflow) and posterior (inflow) portions (5 cases). Harris and Farber, following Spitzer's (1923) theory of transposition, have suggested that the accessory septum on the floor of the right ventricle may represent an hypertrophied trabeculum septomarginalis, while the upper accessory septum may be contributed to by three structures present in more primitive hearts; the anterior tricuspid ledge of the reptilian heart, the crista supraventricularis of the mammalian heart, and the bulbo-ventricular ridge. In Case 2 both these accessory septa are present.

The tricuspid valve cusps showed thickening and vegetations in four, and complete atresia in three cases. The ductus arteriosus was closed in nine cases.

\section{SUMmaRY}

Two hearts are described, each of which showed an unusual position of the atrial appendages, namely that they lay side by side instead of enclosing the great vessels. The name of juxtaposition of the atrial appendages is suggested for this anomaly.

In the first heart the two appendages lay to the right of both great vessels. This condition does not appear to have been previously reported. It was associated with such hypoplasia of the right side of the heart as to cause a functional cor biloculare.

In the second both appendages lay to the left of both great vessels. This condition has been reported in ten previous cases which, with our case, form a sub-group of morbus coeruleus, having several other abnormalities in common, including in ten out of eleven cases the special feature of diminished pulmonary blood flow.

I am indebted to Mr. A. T. Andreasen and to Dr. Maurice Campbell for help in the preparation of this paper. Dr. J. E. Edwards kindly brought to my notice two of the cases cited.

\section{REFERENCES}

Abbott, M. E. (1927). In Modern Medicine, Osler, W., and Macrae, T., 4th ed., Vol. 4.

Birmingham, A. (1893). J. Anat. and Physiol., 27, 139.

Bredt, H. (1935-36). Arch. Path. Anat., 296, 114.

Dunner, L. (1914). Zeitsch. Klin. Med., 80, 217.

Evans, W. (1933). Quart. J. Med., (N.S.) 2, 1.

Harris, J. S., and Farber, S. (1939). Arch. Path., 28, 427.

Huebschmann, P. (1921). Verhand. Deutsch. Path. Gesel., 18, 174.

Kettler, L. (1932-33). Arch. Path. Anat., 287, 10.

Rogers, H. M., Cordes, J. H., and Edwards, J. E. (1950). Amer. J. Dis. Child., 80, 427.

Spitzer, A. (1923). Arch. Path. Anat., 243, 81.

Taussig, H. B. (1947). Congenital Malformations of the Heart. p. 510. The Commonwealth Fund, New York.

Wenner, O. (1909). Arch. Path. Anat., 196, 127.

\footnotetext{
* Transposition of the great vessels is defined by Abbot (1927) as an alteration of the two great vessels relative to the ventricles of the heart, or to each other at their origins, so that they either spring from reversed ventricles, the aorta from the right, and the pulmonary artery from the left chamber (complete transposition) or from the ventricle to which they normally belong but in reversed relationship (corrected transposition). Partial transposition is that variety where one vessel is transposed so that both spring from the same chamber.
} 